\title{
Fuzzy logic-based maximum power point tracking solar battery charge controller with backup stand-by AC generator
}

\author{
Gilfred Allen M. Madrigal ${ }^{1}$, Kristin Gail Cuevas ${ }^{2}$, Vivien Hora ${ }^{3}$, \\ Kristine Mae Jimenez ${ }^{4}$, John Niño Manato ${ }^{5}$, Mary Joy Porlaje ${ }^{6}$, Benedicto Fortaleza ${ }^{7}$ \\ ${ }_{1,2,3,4,5,6}$ Electronics Engineering Department, Technological University of the Philippines, Philippines \\ ${ }^{7}$ Mechanical Engineering Department, Technological University of the Philippines, Philippines
}

\begin{tabular}{l}
\hline Article Info \\
\hline Article history: \\
Received Jan 11, 2019 \\
Revised Apr 14, 2019 \\
Accepted May 9, 2019 \\
\hline
\end{tabular}

\section{Keywords:}

Buck-boost converter

Charge controller

Fuzzy logic

Maximum power point tracking (MPPT)

\begin{abstract}
This paper presents a Fuzzy-based Maximum Power Point Tracking Solar Battery Charge Controller with backup stand-by AC generator. This study is developed to provide a maximum power point tracking battery charge controller using fuzzy logic algorithm for isolated areas that uses solar panels and AC generators. Fuzzy Logic Toolbox in MATLAB and Arduino IDE were used in implementing fuzzy logic algorithm. Fuzzy logic is a mathematical system where something can be represented in continuous values between 0 and 1 . It basically represents systems based on human reasoning. The hardware comprises of four components - the switched mode power supply, the source switching circuit, buck-boost converter and the diversion load controller. The pre-testing conducted based on the methodology indicates that the proposed charge controller is efficient in maximizing the input power that enters the charge controller under different conditions. The current efficiency rate of the charge controller is $96.02 \%$. The average battery charging time for a fully-discharged $12 \mathrm{~V}$ Lead-Acid Battery using AC source, DC source and both AC and DC sources are 2 hours and 30 minutes, 8 hours and 15 minutes and 5 hours and 30 minutes, respectively, while discharging took 3 hours and 40 minutes with two 30watt floodlight load.
\end{abstract}

Copyright $@ 2019$ Institute of Advanced Engineering and Science. All rights reserved.

\section{Corresponding Author:}

Gilfred Allen M. Madriga,

Electronics Engineering Department,

Technological University of the Philippines,

Ayala Boulevard, Ermita, Manila 1000, Philippines.

Email: gilfredallen_madrigal@tup.edu.ph

\section{INTRODUCTION}

Electricity is a basic need to every human. However, in some areas in the Philippines weren't provided with electricity due to its distance from the main grid. People from these isolated communities tend to use renewable energy power plants and store the created electricity in batteries. The most common and easily harvested renewable energy that produces electricity is the solar energy [1].

Charging batteries using available renewable energy will solve the problem of inconveniences caused by living in isolated areas. However, if overcharging of the batteries occurs, battery performance or even its lifespan can be reduced. To prevent this, a charge controller is used. To attain the most effective charging and discharging status of the battery, a fuzzy control strategy is developed [2].

Maximum power point tracking (MPPT) is a method used to extract power from the solar panel which should be matched with the load or battery for maximum power (the highest point in the PowerVoltage Curve as shown in Figure 1 will be ensured. It is best used at different solar irradiances. Charging without an MPPT controller will result to wasted power [3]. Charge control must supply the battery with a higher voltage than the battery's rated voltage to overcome the battery's internal resistance [4]. 


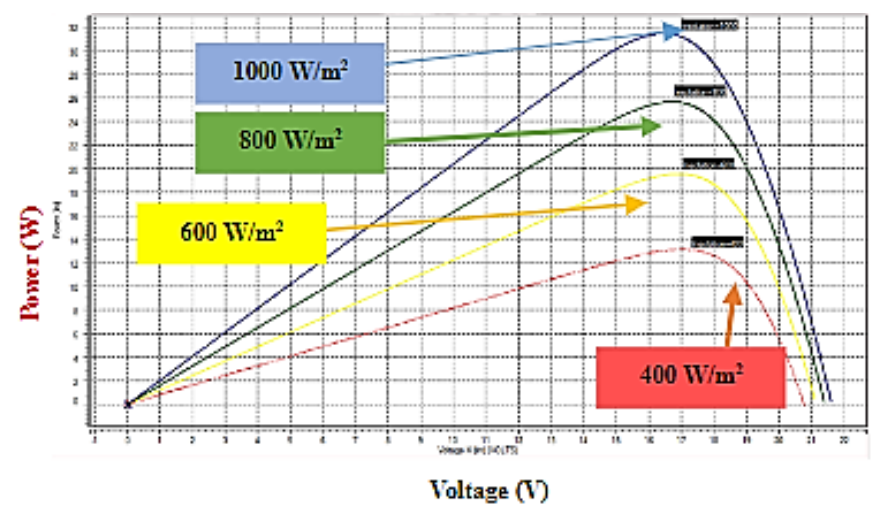

Figure 1. Power-voltage P-V characteristic curve of the solar panel under varying irradiances (400, 600, 800, and $1000 \mathrm{~W} / \mathrm{m} 2$ ) at $250 \mathrm{C}$

This research study is for the design of a charge controller using MPPT for battery charging. It controls the electric current that flows from a hybrid AC and DC source to the battery where AC is supplied by a generator while DC comes from the photovoltaic system. A battery charge controller of a hybrid renewable energy sources and standby power source from the main grid was done [5]. In a hybrid system, a solar panel is often included to make up for the erratic factors that affect the harvesting of electricity.

A PV charger using SEPIC converter was proved to be effective in MPPT [5]. This charger needs to regulate the charging of the battery for better state-of-charge and for the battery to last.

The researchers used MPPT for buck-boost converter based on fuzzy logic. Fuzzy logic controller is used to manage the output voltage of the buck-boost converter to obtain a desired output [6]. Also, stepping up the input voltage can be done using Fuzzy algorithm [6]. Using fuzzy control [7], the dependability of the converter and the power acquired can be enhanced, and its output can result to less overshoots.

Most studies about battery charge controller are implemented with MPPT system. One of these [8] focused on extracting maximum output power deserting the changes in solar irradiation and atmospheric temperature using MPPT in PV system. Incremental Conductance [9, 10-11], Perturb and Observe [8-9, 11], and Ripple Correlation Control [9-10,12] method are the most common algorithms implementing MPPT but the Fuzzy Logic Algorithm is much better than the said 3 algorithms in terms of stability and high response rate. Also, MPPT can be integrated in buck-boost converter. MPPT-based buck boost converter that changes a DC voltage into a higher or lower voltage level than the input voltage efficiently is presented in [13]. A hybrid PV system and wind power system with Fuzzy controller was studied and proposed to obtain the required SOC value designed for the charging and discharging state of the battery [14].

\section{PROPOSED METHOD}

This section details the theoretical knowledge used by the researchers in achieving maximum power.

\subsection{Buck-Boost Converter}

Numerous studies, journals and published papers are studied and consulted for the design of the circuit. A DC-DC Buck Boost Converter was designed and implemented using Fuzzy Logic Controller, PI controller and combined algorithm [15]. Figure 1 shows the schematic diagram of a buck boost converter. When the switch is on, the current will pass through the MOSFET, but it will be blocked by the diode. This will result for the current to flow through the inductor, resistor and out of the capacitor. When the switch is off, the current will flow from the inductor through the resistor, capacitor and diode. This will discharge the inductor and to be charged again in the next cycle [16-17].

Figure 2 illustrates the operation of the buck boost converter with its input coming from a $150 \mathrm{~W}$ monocrystalline solar panel. The voltage produced by the solar panel depends on the intensity of the sunlight ranging from $0 \mathrm{~V}-22 \mathrm{~V}$. This voltage must be bucked or boosted to meet the charging voltage of the battery which is $13.8 \mathrm{~V}$ for their long term capacity [4]. Also, controlling the input voltage of the battery can increase its lifespan for long term use to attain high SOC and prevent battery life from deteriorating, a proper charge/discharge control approach must be considered [18]. 


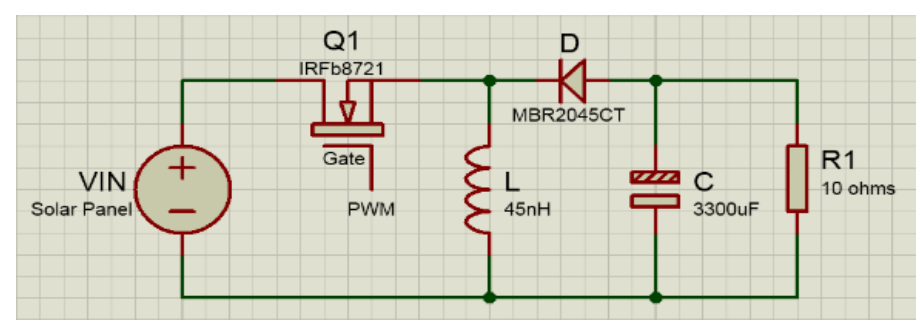

Figure 2. Buck Boost Converter Inverting Topology [15-17]

\subsection{Fuzzy Logic}

The Fuzzy logic controller (FLC) is a mathematical system that converts a language control strategy [19] and can be acquired using the values between 0 and 1. It can be very suitable for obtaining the linearity and time invariance of a system or when the human understanding is different from its model [19].The fuzzy logic system has four main parts, namely: fuzzification, rule base, inference engine, and defuzzification.

Fuzzification involves converting the input values to linguistic labels. To relate the input values to the output model properties, if-then rules are formed in the rule base. The rules are combined to form output control actions which are applied to the inference engine. The inference engine which is carried out by using Mamdani's method determines the degree of the fuzzy input with respect to each rule and decides which rules are to be used according to the input field.

Defuzzification is performed according to the membership function of the output variable. It uses the center of gravity to compute the output of this fuzzy logic system. This is the most popular defuzzification method and is commonly used in actual applications. Buck-boost converter input flowchart as shown in Figure 3.

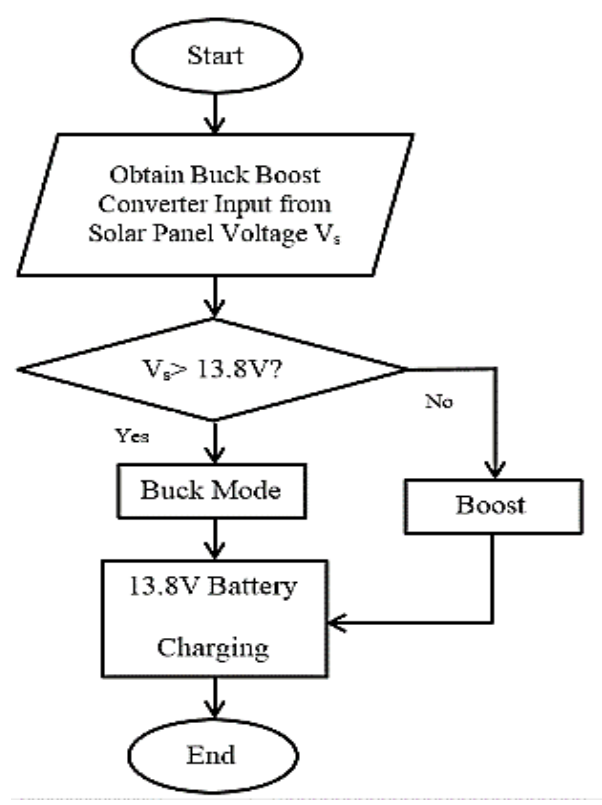

Figure 3. Buck-Boost Converter Input Flowchart

\section{RESEARCH METHOD}

The block diagram of the charge controller is shown in Figure 4. It has two sources, the AC source or the generator and the DC source or the solar panel. The output of the generator is converted into DC from single-phase AC while the output of the solar panel is fed to the buck boost converter. The output voltage of the buck boost converter is being monitored by the voltage sensor to become the input of the Arduino which implements the Maximum Power Point Tracking system using the fuzzy logic algorithm that determines the duty cycle that is needed for the switching of the MOSFETs in the buck boost converter. The outputs of the 
AC/DC converter and the buck boost converter are fed to the Source Switching Circuit which controls whichever output is fed to the load. This circuit is used to switch among the sources based on its availability. This controller circuit can switch between the DC and AC source. Once the battery is fully charged, the output of the switching circuit is diverted to a dummy load that prevents damage to the system and the battery.

\subsection{Hardware Development}

The hardware of the system is composed of a Switched Mode Power Supply, regulator, Arduino Mega 2560, Buck Boost Converter, source switching circuit, and diversion load controller. It also includes fan and LCD. These parts of the system are discussed in this section.

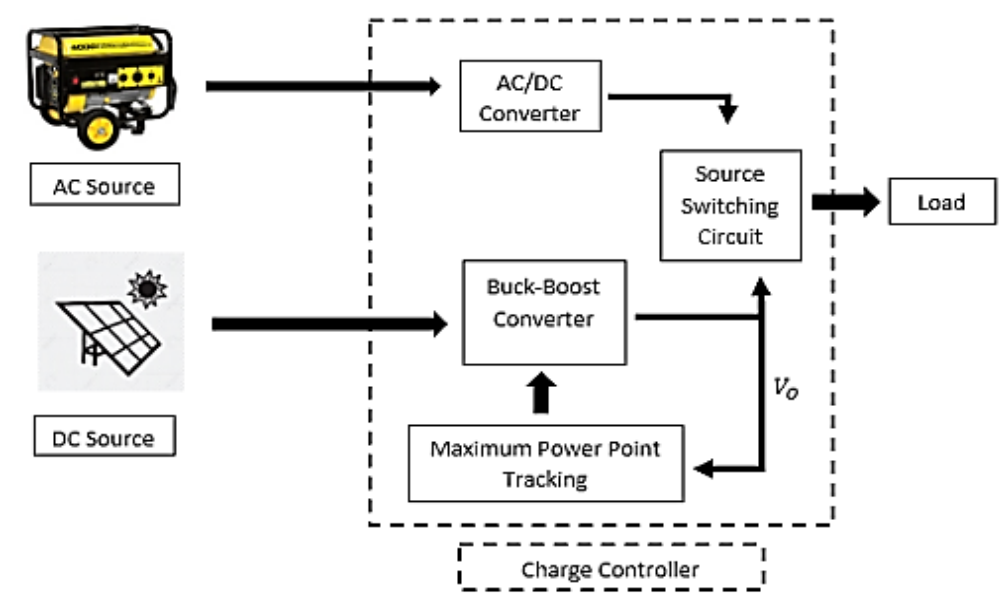

Figure 1. Block diagram of the system

Figure 5 shows the circuits used in the project. (a) Switched Mode Power Supply converts AC voltage of the generator used into $13.8 \mathrm{~V}$ DC that is needed to charge the battery, (b) Regulator Circuit steps down the produced voltage of the SMPS needed by Arduino Mega 2560, (c) Arduino Mega and Uno uploads the code into the hardware for fuzzy logic and diversion load controller respectively, (d) Buck Boost Converter Circuit steps down or steps up the input DC voltage into 13.8V, (e) Source Switching Circuit switches the default DC Source into AC Source whenever the power produced by the Solar Panel is insufficient for charging and (f) Diversion Load Controller Circuit prevents overcharging and damaging of the battery.
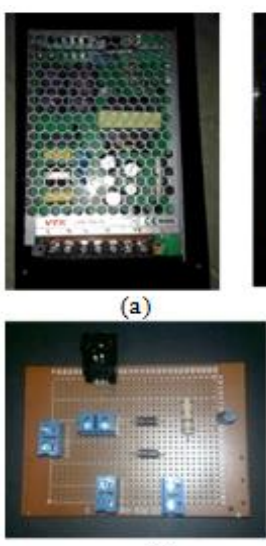

(d)

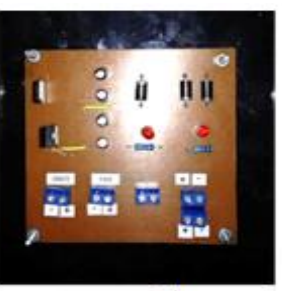

(b)

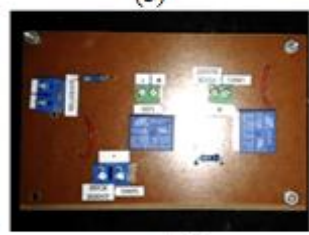

(e)

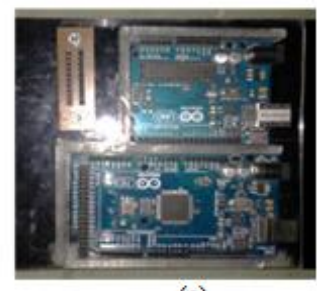

(c)

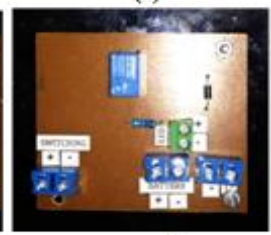

(f)

Figure 5. Devices of the Project: (a) Switched Mode Power Supply, (b) Regulator Circuit, (c) Arduino, (d) Buck Boost Converter Circuit, (e) Source Switching Circuit and (f) Diversion Load Controller Circuit 


\subsection{Fuzzy Inference Model for MPPT}

The system flowchart of the software is shown in Figure 6. It shows the process of obtaining the inputs for the fuzzy logic controller. It starts from assigning the value of the reference voltage into that of the desired voltage output. The output voltage of the buck boost converter is compared to the reference voltage and if they are equal, it means that the output of the dc-dc converter is already the desired $13.8 \mathrm{~V}$ to supply to the battery. If the output voltage is lesser or greater than the reference voltage, the error and change of error is determined and will be the inputs of the fuzzy logic controller, thus producing the duty cycle to determine the switching pulses to be delivered to the gate of the MOSFET of the buck converter until the desired output voltage is achieved.

a. Inputs

Two inputs will undergo fuzzification which are the Error and Change of Error. The Error is defined as the difference between the reference voltage and the measured output voltage of the buck boost converter; it is designed ranging from -13.8 to 13.8. The Change of Error is calculated from the difference of the error and the previous value of error; the change of error does not produce very large values because the error values are almost the same from its previous values, so it was limited in the range -5 to 5 .

b. Output the system.

The output is the duty cycle and is ranged from 0 to 1 representing the 0 to 100 percent duty cycle of

c. FIS Type

There are several types of membership functions but due to their simple formulas and computational efficiency, both triangular MFs and trapezoidal MFs have been used extensively, especially in real-time implementations [20]. Triangular membership function was used in the fuzzy logic toolbox for the inputs and output and each is assigned to five linguistic variables, namely NB (Negative Big), NS (Negative Small), ZE (Zero), PS (Positive Small) and PB (Positive Big). The triangular membership function is usually used in fuzzy logic applications because of its simplicity compared to the other types of membership functions.

d. Defuzzification

The Center of Gravity ( $\mathrm{CoG})$ is used in defuzzification. It is also called Center of Area (CoA) because it is similar in determining the center of gravity in physics and it is the method used to obtain the duty cycle of the system.

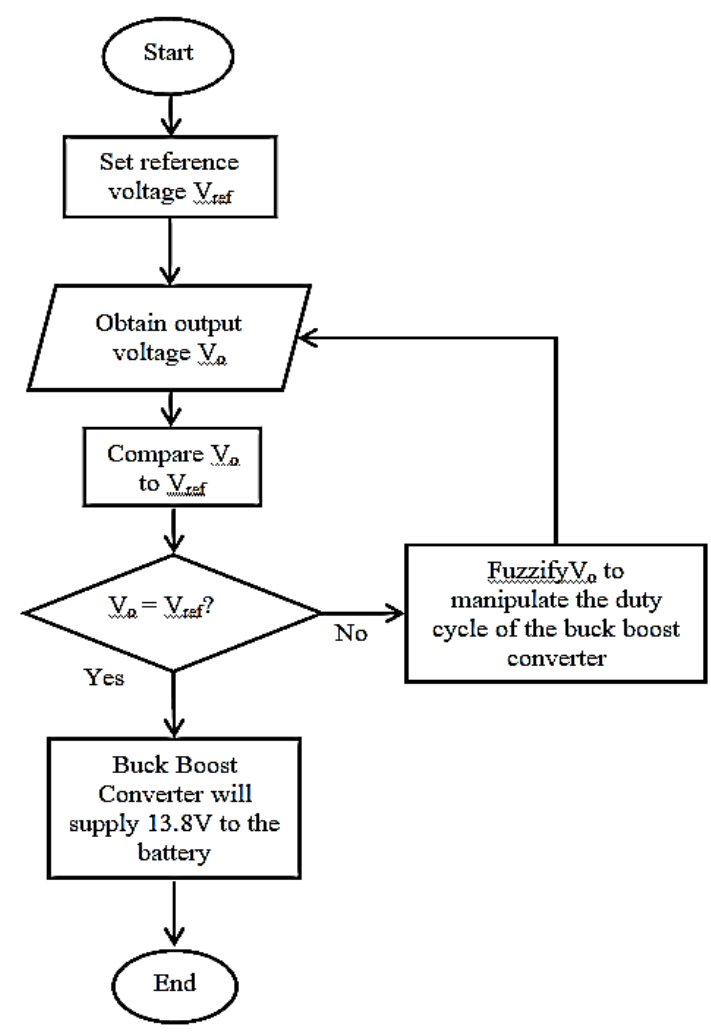

Figure 6. Fuzzy Control input flowchart 
The Fuzzy Logic Toolbox in Figure 7 provides functions to model, analyse and simulate systems based on fuzzy logic. The toolbox lets users design the system using different functions and rules depending on the needs of the system.

Triangular membership function was used in the fuzzy logic toolbox for the inputs and output and each is assigned to five linguistic variables, namely NB (Negative Big), NS (Negative Small), ZE (Zero), PS (Positive Small) and PB (Positive Big).

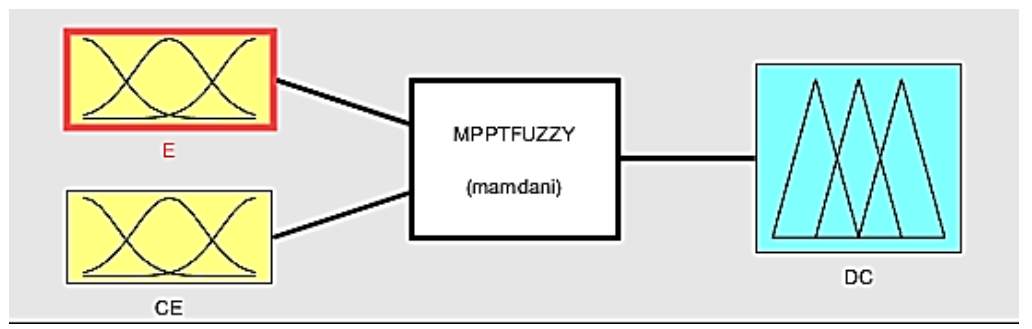

Figure 7. Fuzzy Logic Toolbox interface

Table 1 consists of the ranges of the five membership functions of Error, Change of Error and Duty Cycle. Fuzzy rules and membership functions can be established when the weather changes to solve the MPPT problem. From the five membership functions for each of the inputs, it produces twenty-five rules to determine the fuzzy outputs as seen on Figure 8. These rules are presented in the MATLAB Fuzzy Logic Designer as if-then statements.

Table 1. Membership Function Range

\begin{tabular}{cccccc}
\hline Variable & NB & NS & ZE & PS & PB \\
\hline Error (V) & -13.8 to -6.9 & -13.8 to 0 & -6.9 to 6.9 & 013.8 & 6.9 to 13.8 \\
Change of Error (V) & -5 to -2.5 & -5 to 0 & -2.5 to 2.5 & 0 to 5 & 2.5 to 5 \\
Duty Cycle $(\%)$ & 0 to 0.25 & 0 to 0.5 & 0.25 to 0.75 & 0.5 to 1 & 0.75 to 1 \\
\hline
\end{tabular}

\begin{tabular}{|c|l|l|l|l|l|}
\hline EE & NB & NS & ZE & PS & PB \\
\hline NB & NB & NB & NS & NS & ZE \\
\hline NS & NB & NS & NS & ZE & PS \\
\hline ZE & NS & NS & ZE & PS & PS \\
\hline PS & NS & ZE & PS & PS & PB \\
\hline PB & ZE & PS & PS & PB & PB \\
\hline
\end{tabular}

Figure 8. Fuzzy Rule Table

\subsection{Testing Procedure}

a. Efficiency of the Fuzzy Logic Controller

The Fuzzy Logic Controller is tested by measuring the output of the buck boost converter to check if the MOSFET will switch on or off using an LED when the Arduino sends a HIGH or LOW to the gate of the MOSFET.

b. Battery Charge Controller Efficiency

The efficiency of the battery charge controller is measured by the following:

1. Record the values of Irradiance, $\mathrm{V}_{\mathrm{MPP}}, \mathrm{I}_{\mathrm{MPP}}, \mathrm{V}_{\mathrm{OUT}}$ and $\mathrm{I}_{\mathrm{OUT}}$ of the system.

2. The VOUT column is averaged and then divided by the desired output voltage 13.8 to get the efficiency of the system.

c. Maximum Power Point Tracking Efficiency

The Maximum Power Point Tracking efficiency is measured by the following:

Fuzzy logic-based maximum power point tracking solar battery charge... (Gilfred Allen M. Madrigal) 
1. Record the expected maximum power and the measured power by multiplying the voltages and current obtained.

2. Record the expected maximum power and the measured power and measure how big the power loss to acquire the efficiency.

d. Charging and Discharging Time of the Battery

Measure the time it takes to charge the battery when the AC and DC source are used. The discharge time is also recorded when the battery is used to power up the flood lights used as load.

\subsection{Formulas}

The following formulas are used in the project:

a. For Buck-Boost Converter

The most important for designing the Buck-Boost converter are total power loss (1), and its efficiency (2).

$$
\begin{aligned}
& \mathrm{P}_{\mathrm{LS}}=\mathrm{P}_{\mathrm{rDS}}+\mathrm{P}_{\mathrm{SW}}+\mathrm{P}_{\mathrm{D}}+\mathrm{P}_{\mathrm{rL}}+\mathrm{P}_{\mathrm{rC}} \\
& \mathrm{n}=\frac{\mathrm{P}_{\mathrm{O}}}{\mathrm{P}_{\mathrm{O}}+\mathrm{P}_{\mathrm{LS}}}
\end{aligned}
$$

where $P_{L S}$ is the total power loss, $P_{r D S}$ is the MOSFET conduction loss, $P_{S W}$ is the switching loss, $P_{D}$ is the diode conduction loss, $\mathrm{P}_{\mathrm{rL}}$ is the loss in the ESR of the inductor, $\mathrm{P}_{\mathrm{rC}}$ is the loss in the ESR of the filter capacitor, $\mathrm{n}$ is the efficiency of the Buck-Boost converter, and $\mathrm{P}_{\mathrm{O}}$ is the output power.

b. For Fuzzy Logic Algorithm System

For testing the efficiency of the system, the following formula is used:

$$
\begin{aligned}
& \text { Error }_{1(\mathrm{AVE})}=\frac{\text { Error }_{\mathrm{T} 1}+\text { Error }_{\mathrm{T} 2}+\text { Error }_{\mathrm{T} 3}+\cdots+\text { Error }_{\mathrm{T} 10}}{\text { number of trials }} \\
& \text { Error }_{2(\mathrm{AVE})}=\frac{\text { Error }_{\mathrm{T} 1}+\mathrm{Error}_{\mathrm{T} 2}+\text { Error }_{\mathrm{T} 3}+\cdots+\text { Error }_{\mathrm{T} 10}}{\text { number of trials }}
\end{aligned}
$$

c. For battery efficiency

The efficiency of the battery charge controller is computed using (5):

$$
\text { Efficiency }=\frac{\mathrm{V}_{\text {OUT }}}{\mathrm{V}_{\text {REF }}} \times 100
$$

where $\mathrm{V}_{\mathrm{OUT}}$ is the output voltages and $\mathrm{V}_{\mathrm{REF}}$ is the reference voltage, which is $13.8 \mathrm{~V}$.

d. For Maximum Power Point Tracking Effeciency

The efficiency of the Maximum Power Point Tracking capability of the system is obtained using (6):

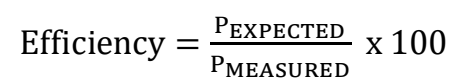

\section{RESULTS AND DISCUSSION}

This section presents the results of the methodologies done in section 4 of this paper. This includes presentation of the results of the data gathered.

\subsection{Efficiency of the Fuzzy Logic Controller}

Table 2 specifies at which voltage does the Fuzzy Logic Algorithm starts the buck or boost mode. The fuzzy logic controller has a high accuracy in giving switching pulses to the MOSFET of the buck boost converter. Applying (3) and (4), where Error $_{\text {(AVE) }}$ is the average error of the controller for buck, Error $_{\text {(AVE) }}$ is the average error for boost, and Error T1 $_{\text {to }}$ Error $_{\text {T10 }}$ is the error on the first trial up to the tenth trial, the computed average error of the controller is 0.105 for the Buck Mode and 0.215 for the Boost Mode. Having this small error, means that the Fuzzy Logic Controller can give switching pulses to the buck boost converter that can make it produce an output voltage close to the reference voltage which is needed by the battery. 


\begin{tabular}{ccccc}
\multicolumn{5}{c}{ Table 2. Voltages at Buck and Boost Mode } \\
\hline \multirow{2}{*}{ Trial } & $\begin{array}{c}\text { Voltage at } \\
\text { which Buck } \\
\text { Mode Starts }\end{array}$ & $\begin{array}{c}\text { Error } \\
\left(\mid \mathrm{V}_{\text {ref }}-\right.\end{array}$ & $\begin{array}{c}\text { Voltage at } \\
\text { which Boost } \\
\left.\mathrm{V}_{\text {buck }} \mid\right)\end{array}$ & $\begin{array}{c}\text { Error }_{2} \\
\left(\mid \mathrm{V}_{\text {ref }}-\right.\end{array}$ \\
& Mode starts & $\left.\mathrm{V}_{\text {boost }} \mid\right)$ \\
\hline 1 & $13.94 \mathrm{~V}$ & 0.14 & $13.45 \mathrm{~V}$ & 0.35 \\
2 & $13.81 \mathrm{~V}$ & 0.01 & $13.71 \mathrm{~V}$ & 0.09 \\
3 & $13.91 \mathrm{~V}$ & 0.11 & $13.67 \mathrm{~V}$ & 0.13 \\
4 & $13.89 \mathrm{~V}$ & 0.09 & $13.76 \mathrm{~V}$ & 0.04 \\
5 & $13.96 \mathrm{~V}$ & 0.16 & $13.52 \mathrm{~V}$ & 0.23 \\
6 & $13.89 \mathrm{~V}$ & 0.09 & $13.62 \mathrm{~V}$ & 0.18 \\
7 & $13.84 \mathrm{~V}$ & 0.04 & $13.64 \mathrm{~V}$ & 0.16 \\
8 & $13.96 \mathrm{~V}$ & 0.16 & $13.52 \mathrm{~V}$ & 0.28 \\
9 & $13.99 \mathrm{~V}$ & 0.19 & $13.32 \mathrm{~V}$ & 0.48 \\
10 & $13.86 \mathrm{~V}$ & 0.06 & $13.59 \mathrm{~V}$ & 0.21 \\
& Average & 0.105 & Average & 0.215 \\
\hline
\end{tabular}

\subsection{Battery Charge Controller Efficiency}

Table 3 has six columns, the trial number, the Irradiance which is the amount of sunlight that strikes the solar panel, the IMPP and VMPP are the current and voltage from the solar panel that enters the system, the IOUT and VOUT are the current and voltage that the system produces.

In getting the efficiency of the battery charge controller, 10 trials were made, and using (5), an efficiency of $94.85 \%$ was acquired.

Table 3. Efficiency of Battery Charge Controller

\begin{tabular}{cccccc}
\hline Trial & Irradiance & $\mathrm{I}_{\mathrm{mpp}}(\mathrm{A})$ & $\mathrm{V}_{\mathrm{mpp}}(\mathrm{V})$ & $\mathrm{I}_{\text {out }}(\mathrm{A})$ & $\mathrm{V}_{\text {out }}(\mathrm{V})$ \\
\hline 1 & 300 & 1.44 & 14.26 & 1.37 & 13.1 \\
2 & 400 & 1.62 & 14.57 & 1.52 & 12.9 \\
3 & 550 & 2.05 & 14.3 & 1.84 & 13 \\
4 & 880 & 1.93 & 12.32 & 1.75 & 12.8 \\
5 & 1000 & 1.76 & 11.9 & 1.63 & 12.7 \\
6 & 1200 & 1.74 & 15.02 & 1.69 & 13 \\
7 & 1600 & 2.28 & 12.71 & 2.12 & 12.9 \\
8 & 1800 & 0.71 & 11.9 & 0.58 & 12.7 \\
9 & 1900 & 1.06 & 18 & 1.22 & 13.8 \\
10 & 2000 & 0.98 & 18.47 & 1.14 & 13.9 \\
\hline
\end{tabular}

\subsection{Maximum Power Point Tracking Efficiency}

The Maximum Power Point Tracking efficiency is computed by comparing the expected input power and measured input power of the system to determine how big or how small the tracking error is. Each efficiency is obtained by dividing the PMEASURED by PEXPECTED. In Table 4, 10 trials were only shown but 28 trials were used in computing the efficiency of the Maximum Power Point capability of the system. Using (6), efficiency of each trial was computed. After getting the efficiency for each trial, it is averaged to acquire the total efficiency of the maximum power point tracking capability of the system. $88.235 \%$ is the calculated efficiency of tracking the maximum power.

Table 4. Maximum Power Point Tracking Efficiency

\begin{tabular}{cccc}
\hline Trial & $\begin{array}{c}\text { PEXPECTED } \\
(\mathrm{W})\end{array}$ & $\begin{array}{c}\text { PMEASURED } \\
(\mathrm{W})\end{array}$ & $\begin{array}{c}\text { Tracking } \\
\text { Efficiency }\end{array}$ \\
\hline 1 & $19.08 \mathrm{~W}$ & $16.836 \mathrm{~W}$ & $88.24 \%$ \\
2 & $18.1006 \mathrm{~W}$ & $15.9486 \mathrm{~W}$ & $88.11 \%$ \\
3 & $16.668 \mathrm{~W}$ & $15.12 \mathrm{~W}$ & $90.71 \%$ \\
4 & $16.506 \mathrm{~W}$ & $15.411 \mathrm{~W}$ & $93.37 \%$ \\
5 & $16.8168 \mathrm{~W}$ & $14.5704 \mathrm{~W}$ & $86.64 \%$ \\
6 & $14.4378 \mathrm{~W}$ & $13.5897 \mathrm{~W}$ & $94.13 \%$ \\
7 & $15.2056 \mathrm{~W}$ & $12.88 \mathrm{~W}$ & $84.71 \%$ \\
8 & $29.315 \mathrm{~W}$ & $23.92 \mathrm{~W}$ & $81.60 \%$ \\
9 & $23.6034 \mathrm{~W}$ & $19.608 \mathrm{~W}$ & $83.07 \%$ \\
10 & $26.1348 \mathrm{~W}$ & $21.97 \mathrm{~W}$ & $84.06 \%$ \\
\hline
\end{tabular}




\subsection{Charging and Discharging Time of the Battery}

Figure 9 illustrates the battery voltage and charging time using different sources with a 30 minutes interval per sample. In this, the charging duration per source varies greatly with AC source as the shortest, then AC-DC source, and lastly the DC source. The battery voltage of the AC source rises abruptly while with the DC source, it rises gradually. Using AC-DC source, there's a sudden increase of the battery voltage of when the source switched from DC to AC. The charging current and duration of the different sources is shown in Figure 10 with samples taken every 30 minutes. Having the shortest time of charging, AC source is observed that the charging current abruptly decreases at first then gradually decreases. Charging using DC source took more time due to varying charging current which depends on the time of the day. Furthermore, on AC-DC source, the charging current on the DC part is decreasing and abruptly increases when switched to AC.

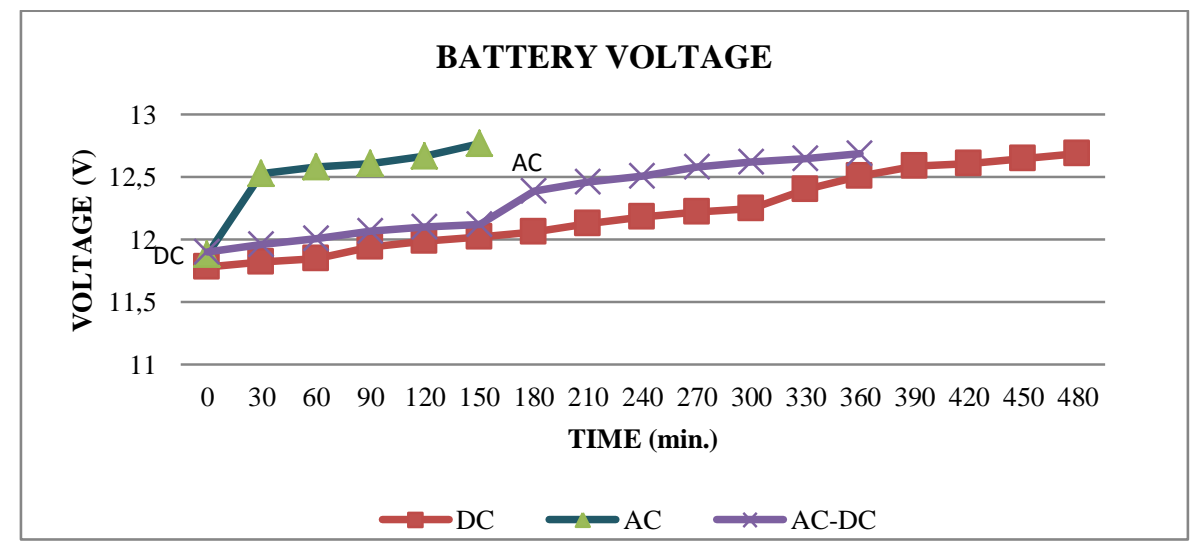

Figure 9. Battery voltage while charging using the different sources

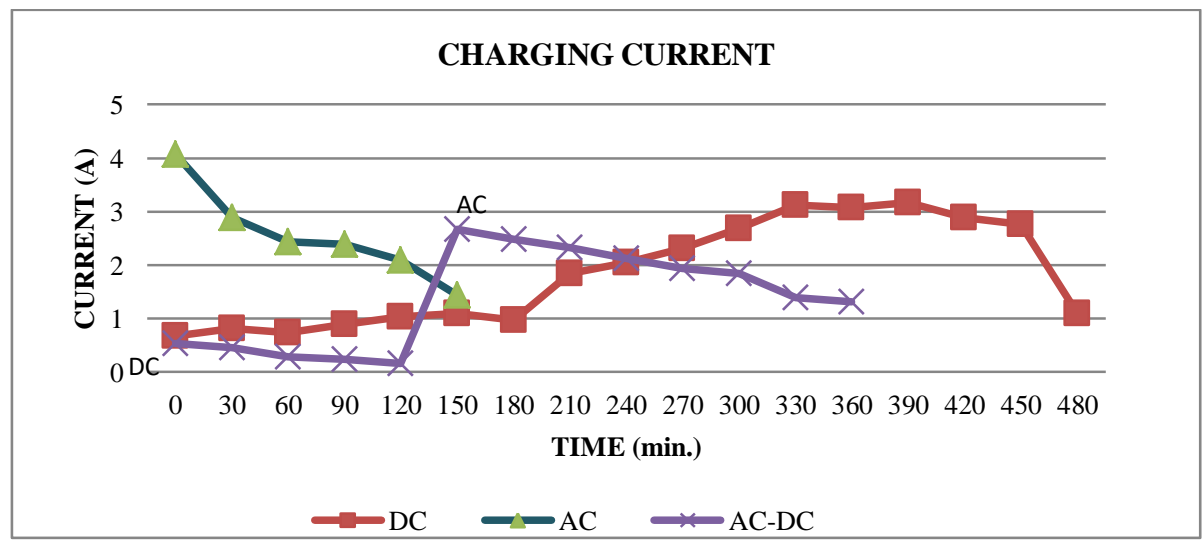

Figure 10. Charging current of different sources

Figure 11 displays the battery voltage while discharging with the two 30-watt floodlight. It shows that on the first 30 minutes, the battery voltage drastically decreases then gradually decreases over time. The discharging of the battery took 3 hours and 30 minutes. Figure 12 shows the delivered current to the two 30watt load. It illustrates that the battery supplies an average current of 3.6475A. The battery took 3 hours and 30 minutes to fully discharge the battery. 


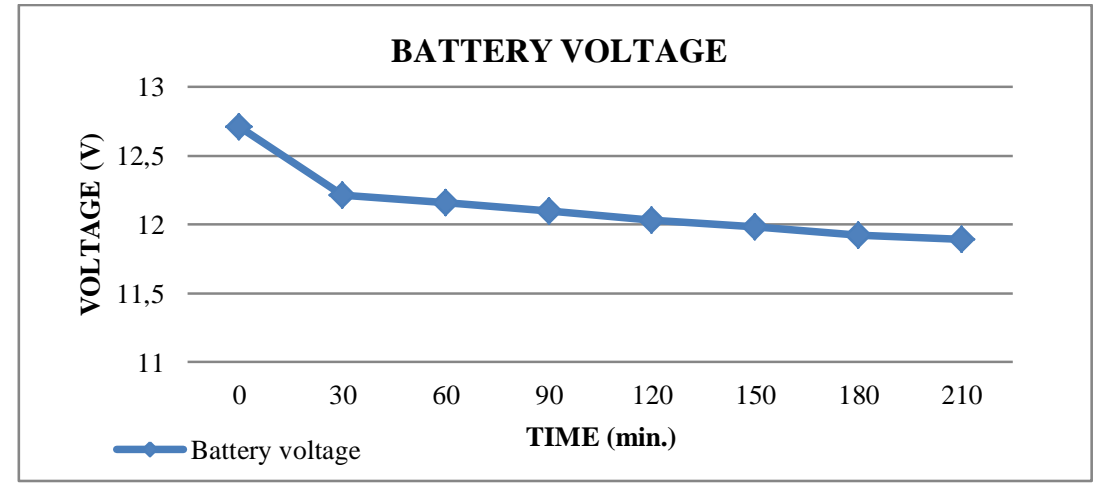

Figure 11. Battery voltage while discharging

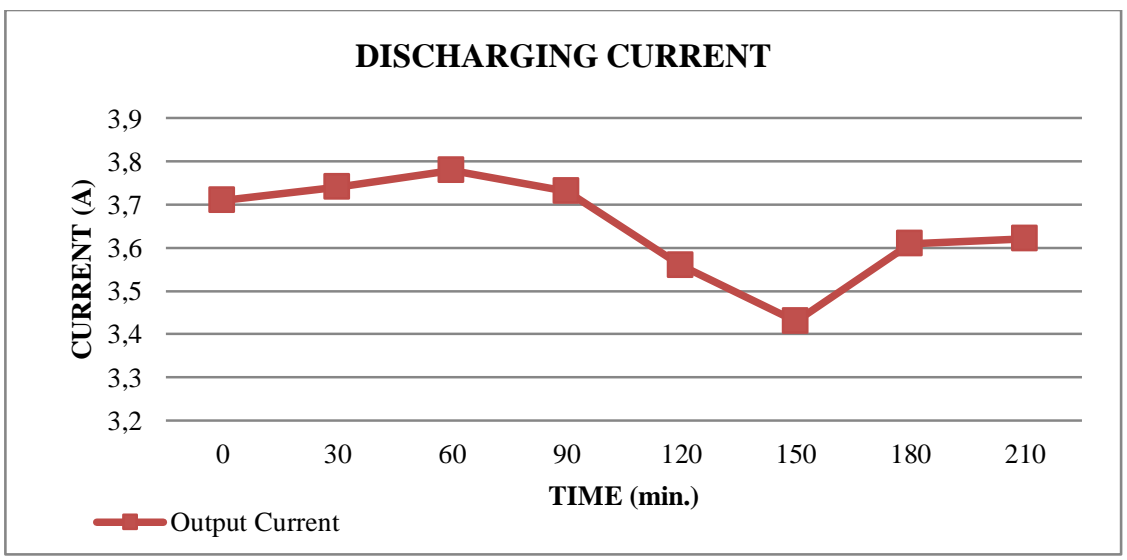

Figure 12. Current delivered to the two 30-watt load

\section{CONCLUSION}

The effectiveness of the Fuzzy Logic Algorithm was observed and found out that it has a high efficiency rate because it produces an output voltage close to the reference voltage by having a small amount of error. In charging a $12 \mathrm{~V}$ Lead-Acid battery using the system, it was determined that the average battery charging time using AC source, DC source and both AC and DC sources are 2 hours and 30 minutes, 8 hours and 15 minutes and 5 hours and 30 minutes, respectively, however, discharging it took 3 hours and 40 minutes with two 30-watt floodlight load.

\section{ACKNOWLEDGEMENTS}

This study is supported by the University Research Development Services Office of the Technological University of the Philippines.

\section{REFERENCES}

[1] S. Hiwale, et al., "An Efficient MPPT Solar Charge Controller," International Journal of Advanced Research in Electrical, Electronics and Instrumentation Engineering, vol. 3, no. 7, pp. 10505-10511, 2014.

[2] V. J. Greshma and R. Sasidharan, "Battery Charging Control using Fuzzy Logic based Controller in a Photovoltaic System," International Advanced Research Journal in Science, Engineering and Technology, vol. 3, no. 3, pp. 114-117, 2016.

[3] M. R. Hamid, et al., "Design and Development of a Maximum Power Point Tracking(MPPT) charge controller for Photo-Voltaic(PV) power generation system," American Journal of Engineering Research (AJER), vol. 5, no. 5, pp. 15-22, 2016.

[4] P. Brand, "Chapter 4 Alternator Charging System," in How To Repair Your Car, Motorbook International, 2006, p. 61.

[5] Giddaiah, et al., "Control of PV Charger System with SEPIC Converter," International Journal of Engineering Research and Application (IJERA), vol. 3, no. 4, pp. 1111-1120, 2003.

Fuzzy logic-based maximum power point tracking solar battery charge... (Gilfred Allen M. Madrigal) 
[6] C.-Y. Won, et al., "A New Maximum Power Point Tracker of Photovoltaic Array Using Fuzzy Controller," Proceedings of 1994 Power Electronics Specialist Conference - PESC'94, Taipei, 2008.

[7] U. Patil and S. R. Jagtap, "Design of Fuzzy Based Controlling System for Buck Converter," International Journal of Advanced Research in Computer Engineering and Technology(IJARCET), vol. 7, no. 6, pp. 1649-1656, 2015.

[8] S. Selvan, et al., "Comparative Study of Perturb and Observe and Fuzzy Logic Control Based MPPT Algorithms," International Journal of Advances in Engineering \& Technology, vol. 7, no. 6, pp. 1649-1656, 2015.

[9] M. G. Batarseh and M. E. Za'ter, "Hybrid maximum power point tracking techniques: A comparative survey, suggested classification and uninvestigated combinations," Solar Energy, vol. 169, pp. 535-555, 2018.

[10] Mudkhi and S. Deshmukh, "Microcontroller Based MPPT Buck-Boost Converter Using 555 Timer," International Journal of Engineering Research \& Technology, vol. 2, no. 7, pp. 1080-1084, 2013.

[11] L. K. Tolentino, et al., "Characterization of a 0.35-Micron-Based Analog MPPT IC at Various Process Corners," Journal of Telecommunication, Electronic and Computer Engineering (JTEC), vol. 10, no. 1-9, pp. 179-186, 2018.

[12] M. Premkumar, et al., "A comparative study and analysis on conventional solar PV based DC-DC converters and MPPT techniques”, Indonesian Journal of Electrical Engineering and Computer Science (IJEECS), vol. 11, no. 3, pp. 831-838, 2018.

[13] S. D. Saranya, et al., "Fuzzy Logic Based Energy Management System for a Microgrid," ARPN Journal of Engineering and Applied Sciences, vol. 10, no. 6, pp. 2663-2669, 2015.

[14] M. Sahin and H. Okumus, "Fuzzy Logic Controlled Buck-Boost DC-DC Converter for Solar Energy-Battery System," in 2011 International Symposium on Innovations in Intelligent Systems and Applications, Istanbul, 2011.

[15] N. H. Baharudin, et al., "Topologies of DC-DC converter in solar PV applications", Indonesian Journal of Electrical Engineering and Computer Science, vol. 8, no. 2, pp. 368-374, 2017.

[16] J. Lubis, et al., "Implementation of Maximum Power Point Tracking on Photovoltaic Using Fuzzy Logic Algorithm," TELKOMNIKA (Telecommunication Computing Electronics and Control), vol. 13, no. 1, pp. 32-40, 2015.

[17] K. Pawar, et al., "Design of Charging and Discharging of Battery in a Renewable Energy based DC Micro-grid," International Journal for Innovative Research in Multidisciplinary Field, vol. 2, no. 10, pp. 245-249, 2016.

[18] S. Kaur and G. Bharti, "Two Inputs Two Outputs Fuzzy Controller System Design Using MATLAB," International Journal of Advances in Engineering, Sciences and Technology, vol. 2, no. 3, pp. 209-218, 2012.

[19] O. A. M. Ali, et al., "Comparison between the Effects of Different Types of Membership Functions on Fuzzy Logic Controller Performance," International Journal of Emerging Engineering Research and Technology, vol. 3, no. 3, pp. 76-83, 2015.

[20] E. R. Shouman, "Forecast Renewable Energy for Electricity to Assist Decision Makers with Case study-Economics Solar Energy for Electricity Supply in Rural Areas in Egypt," International Journal of Applied Engineering Research, vol. 11, no. 5, pp. 3596-3604, 2016. 